\title{
Averting compassion fatigue and burnout. Who should help us conquer our demons?
}

\author{
Tajek B Hassan
}

What makes a good emergency physician (EP) in today's world? If you had to choose one thing what would it be? Is it about being trained to perform and maintain skills in rare life-saving procedures, being adept with an ultrasound probe or mobilising and maintaining your team's morale through a busy shift late at night in the Emergency Department (ED). Or is it much more about being able to consistently role model for your team a compassionate caring attitude through a hectic shift and even more importantly sustain it through a satisfying clinical career.

In their EMJ paper, Dasan et $a l^{1}$ shine a brighter light on a seemingly neglected area of our practice and help us quantify where we are and where we need to be. Although the study is based in the UK, there are valuable lessons for the international community in Emergency Medicine. Indeed, as we know, the phenomenon of 'burnout' is well recognised in almost all spheres of work in the developed world, with medicine providing ever increasing examples. Policymakers and health commissioners will need to pay increasing attention if they are to produce the 'best value for money' from the staff they spend years training at great expense. This applies to attract them into these vital specialties and to retain them for the long term. Equally important in the complex formula of course is the responsibility of the individual and how they care for themselves.

Compassion fatigue is defined as a combination of emotional, physical and spiritual depletion when caring for patients in emotional and physical distress. ${ }^{2}$ Burnout, on the other hand, tends to be more insidious in onset and is characterised by feelings of depersonalisation (cynicism), loss of enthusiasm for work (emotional exhaustion) and low sense of self-worth (personal accomplishment). Burnout leads to a range of poor outcomes. ${ }^{3}$ The causes have been well described and correlate with emotional exhaustion including loss of autonomy as well as negative work attitudes to quality

Correspondence to Dr Tajek B Hassan, Department of Emergency Medicine, Leeds Teaching Hospitals, Gt George St, Leeds General Infirmary, Leeds LS1 3 EX, UK; taj.hassan@nhs.net and safety. Other factors involved include workload, constraining organisational structure, work-life conflicts and resulting negative work attitudes.

The present stresses on the health service in the UK and Ireland are only likely to be heightened in the coming years. The significant funding challenges will add more pressure onto systems that are already creaking and in some parts failing badly. Nor is this unique to the UK. In the USA, for example, ED visits have risen from 35.7 visits/100 population to $44.4 / 100$ in 20 years, while the number of departments has steadily decreased. ${ }^{4}$ Not unsurprisingly, Emergency Medicine tops the league table of burnout among physicians in the USA when corrected for other factors. ${ }^{3}$ Of greater concern, the scale of the challenge in developing systems and countries remains poorly quantified and is an important ongoing workstream for the International Federation for Emergency Medicine.

The most valuable resource to help us out of this quagmire is of course how we care for our staff and support them with better system design, job planning and career structure. They in turn can then be better empowered and enthused to innovate, design and deliver efficient, effective and safer patient centred care. The serious workforce challenges facing Emergency Medicine in the UK and Ireland have been well described over the past 4-5 years and indeed prior to that. However, there is clear evidence that the specialty is not alone and that indeed many front line specialties are similarly affected. Ultimately, these stresses result in poor satisfaction in the workplace, negatively influence direct patient care and shorten or in some cases destroy clinical careers.

Dasan's paper is therefore very timely. It defines using well-validated tools the prevalence of compassion fatigue and satisfaction among NHS Consultants in Emergency Medicine in the UK. The 52\% response rate is a limitation that the authors highlight, but it is comparable with other studies in the field. At first sight, the results seem to surprisingly show that $98 \%$ had average or better than average scores in terms of compassion satisfaction and low likelihood of burnout.
The greater concern were the softer metrics which will merit further research, with one-third reporting increased irritability, medical errors, and 11\% reported making mistakes that did actual harm to patients within the previous 6 months. In addition, $59 \%$ of respondents stated that they intended to retire early. In the context of present workforce pressures, this will only add to the stress in the system if it proves to be accurate.

The paper adds valuable balance to the existing literature which highlights pressures both in Emergency Medicine as well as other specialities. For example, the Royal College of Emergency Medicine in a study in 2012 showed that $62 \%$ felt that their present job plans were unsustainable and that urgent action was needed. ${ }^{5}$ The College has also worked hard to produce a strategy over the past 2 years to highlight those features that can lead to a sustainable and satisfying career. ${ }^{6}$ Similar initiatives are also being progressed by other national and international organisations including the International Federation for Emergency Medicine.

There is no doubt that Emergency Medicine is a fantastically stimulating and satisfying career. However, there is an emerging realisation that those who step forward to becoming trained as EPs should be better supported and cared for by their employers due to the added stressors that the specialty can impose on them. Systems that fail to do this well enough face the consequences of migration away of their very valuable trained senior medical decision makers in an increasingly global emergency healthcare workforce. This in turn leads to increasing fragility within those emergency care systems and results in poor levels of emergency care for the local population. Dasan's paper notes that in systems that are perhaps better resourced such as the recently developed trauma centres in the UK, there seemed to be greater compassion satisfaction scores. This is certainly worthy of further research.

So what is needed now? At the very heart of what we do as EPs is to deliver compassionate, safe care to our patients who arrive at all times of day or night. It is our raison d'etre that provides us with personal satisfaction and indeed re-energises us. We know that when we care for and feedback to our patients and their relatives well it produces such satisfaction for us. In order to do that consistently, EPs themselves must feel supported and satisfied with the work they do and must be proactive in caring for themselves. Good systems value their staff, provide resources that ensure safe patient-centred care and 
support for their teams. The challenge of leading such teams in the often hectic environment of the ED has never been greater. The good news is that there seems to be progress on a number of fronts and each decade brings remarkable positive change in spite of what we might think in the midst of a busy period of 'surge' or exit block. For example, the number of trained EPs in the UK has quadrupled in the last 12 years. This has significantly increased the breadth and depth of senior clinical decision makers for the ED and led directly to better care for our patients especially 'out of hours'. But of course there is still much to do.

Much more work is required in the areas of sustainable job planning for EPs, design of more flexible work patterns for those who need them as well as showcasing career pathways that inspire, attract and will retain the new millennial generation of doctors. Those responsible for fragile emergency care systems are at the forefront of needing to find good sustainable strategies. Government policy makers and employers must work with colleges and expert national bodies to better understand the issues and find tangible solutions both in the short and longer terms. The individual EP also has responsibilities. They must ensure that they find ways to care for themselves that will allow them to optimise their human perform- ance as a teamleader on the ED 'shopfloor' and more importantly keep them satisfied and stimulated for the longer term. Only then can we create resilience for ourselves and better care for our patients. It will also help to keep our inner demons at bay.

Twitter Follow Taj Hassan at @tajekbhassan

Competing interests TH was Chair of the Sustainability Group of the Royal College of Emergency Medicine (2012-14) that published Creating Successful, Satisfying and Sustainable Careers in Emergency Medicine. He also chairs the Sustainable Working Practices Group for the International Federation for Emergency Medicine.

Provenance and peer review Commissioned; internally peer reviewed.
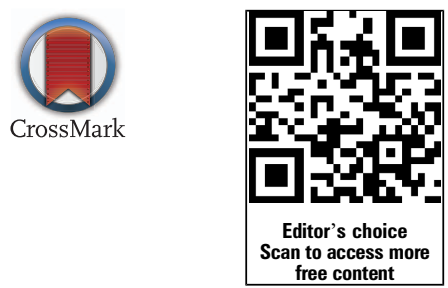

To cite Hassan TB. Emerg Med J 2015;32:586-587.

Received 15 February 2015

Accepted 20 February 2015

Published Online First 13 March 2015

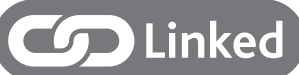

http://dx.doi.org/10.1136/emermed-2014-203671
Emerg Med J 2015;32:586-587.

doi:10.1136/emermed-2015-204752

\section{REFERENCES}

1 Dasan S, Gohil P, Cornelius V, et al. Prevalence, causes and consequences of compassion satisfaction and compassion fatigue in emergency care: a mixed methods study of UK NHS consultants. Emerg Med J 2015;32: 588-94.

2 Figley CR. Compassion fatigue: toward a new understanding of the costs of caring. In: Stamm B. H. (ed.), Secondary traumatic stress: self-care issues for clinicians, researchers, and educators. Baltimore, MD, USA: The Sidran Press, 1995;xxiii:3-28.

3 Shanafelt TD, Boone S, Tan et al. Burnout and satisfaction with work-life balance among US physicians relative to the US population. Arch Intern Med 2012:172:1377-85.

4 Augstine, J. The ED Patients Keep Coming, ACEP Now, January 2015. http://www.acepnow.com/article/ national-hospital-ambulatory-medical-care-survey-datashow-increase-emergency-department-visits/ (accessed 15 Feb 2015).

5 Royal College of Emergency Medicine (2013) Stretched to the limit. http://www.collemergencymed.ac.uk/ Shop-Floor/Professional\%20Standards/Consultant $\%$ 20Working\%20and\%20Job\%20Planning/Stretched\% 20to\%20the\%20limit (accessed 15 Feb 2015).

6 Royal College of Emergency Medicine. Creating successful, satisfying and sustainable careers in Emergency Medicine-Guidance from the College of Emergency Medicine. 2014. http://secure. collemergencymed.ac.uk/Shop-Floor/Service\%20Design \%20\&\%20Delivery/The\%20Emergency\%20Medicine\% 20Workforce/Sustainable\%20working (accessed 15 Feb 2015). 